\title{
Development of a mathematical model for electrode systems in rheoophthalmography
}

\author{
Anna Kiseleva \\ Bauman Moscow State Technical \\ University \\ Moscow, Russian Federation \\ Email:kiseleva.anna.a94@gmail.com
}

\author{
Petr Luzhnov \\ Bauman Moscow State Technical \\ University \\ Moscow, Russian Federation \\ Email:petervl@yandex.ru
}

\author{
Dmitry Shamaev \\ Bauman Moscow State Technical \\ University \\ Moscow, Russian Federation \\ Email:shamaev.dmitry@yandex.ru
}

\begin{abstract}
The problem of estimating the electrical impedance characteristics was solved using the system of impedance diagnostics of blood circulation with the help of mathematical modeling. In this work, the geometry for mathematical modeling was reconstructed; its basic quantitative characteristics were calculated. The working capacity of the model is verified on the basis of theoretical data. An example was shown by using the model to select the optimal positions of the electrodes for conducting electrical impedance studies in rheoophthalmography. As a result, an example of simulation was shown.
\end{abstract}

Keywords - mathematical modeling, electrical impedance, eye, pulse blood filling.

\section{INTRODUCTION}

Mathematical modeling is one of the powerful tools of modern science [1,2]. Unlike experimental studies, the methods of modeling make it possible to change the parameters, characteristics, and properties of the system under investigation in a wide range. Advances in computer technology make it possible to overcome the difficulties of analytical calculations in the study of complex models, which allows to obtain quantitative characteristics [3].

Modeling has become widespread in the field of biomedical technology $[4,5,6]$. This is due to the fact that in the development of complex biomedical systems, mathematical modeling is the only way to assess the quality of their functioning in advance. Moreover, it allows to simplify the design phase synthesis and analysis processing of the data, the implementation of which requires digital computing devices, as well as optimizing control algorithms and external interaction with other systems.

In our paper, the task of estimating the electrical impedance characteristics is solved using the rheoophthalmography system [7,8] with mathematical modeling. Rheophthalmography is an electrical impedance method for the studying pulse oscillations in the blood filling of the eye vessels, based on the graphical recording of changes in the total electrical resistance of tissues. Optimal positions for electrodes have been chosen and a model has been developed for further verification of the results obtained.

\section{MATERIALS AND METHODS}

\section{A. Statement of the problem}

It is necessary to determine the boundary conditions of the solving problem in the compilation of a mathematical model of any system. For the purpose of carrying out a numerical experiment, it is necessary to compile an algorithm for the numerical method for solving equations which is a mathematical model of the process under study. As a result, the model is refined itself and the algorithm is corrected [9].

Methods of mathematical modeling techniques are dynamic systems theory. Tools - differential and difference equations, methods of qualitative theory of differential equations, computer simulation [10,11]. In general, the purposes of modeling can be divided into three main groups: 1) elucidation of the mechanisms of interaction the elements of the system; 2) identification of model parameters from experimental data; 3 ) prediction of the behavior of the system under various external influences. In the framework of this paper we have interested in the accuracy of the data obtained, which can be attributed to the second group of modeling goals [12].

\section{B. The biobject analysis}

The object of research is the frontal part of the head bloodstream, including the ophthalmic arteries. Diagnostic data of blood pulse are obtained with the help of the developed electrodes system. The electrical impedance method is a technique for obtaining diagnostic information by means of non-invasive electrical sounding [13-15]. It is possible to visualize the internal structures of bioobjects using the electrical impedance method due to the fact that different tissues have different electrical conductivity. Blood flow especially affects the electrical conductivity of the tissue. This method has widely used to study the circulation of the brain [14].

The main problem arising in the development of electrode designs for electrical impedance measurement is the achievement of the required accuracy of the results [16-18]. To solve the problem, it is required to place the electrodes

This work was supported by a grant from RFBR (No.18-08-01192). 
around the area under investigation with an accuracy of $5 \mathrm{~mm}$. The selection of the necessary positioning points and verification of the developed structures is carried out by computer simulation.

In this paper, we consider an 6-electrodes system, which is located at eye level (see Fig.1). As a result, it is possible to obtain data of blood filling of the internal carotid, middle cerebral, anterior cerebral and ophthalmic arteries. The diameter of the eye artery is the smallest of the recorded arteries (varies in the range from 0.3 to $0.5 \mathrm{~mm}$ ) [19]. In this work we will carry out simulation for this artery.

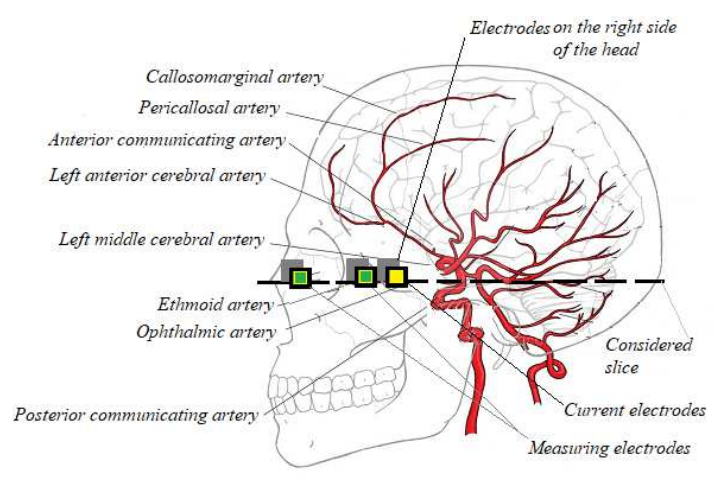

Fig.1. Scheme of electrodes position using the developed system

The ophthalmic artery lies outside of the optic nerve, moving on its way through the optic canal into the orbit [20]. The ophthalmic artery is located only in the front of the head, so we accept the first assumption - in modeling we will consider only the front of the head [21]. The second assumption is that the distribution of equipotential flow lines in the layers of tissues will be enough to obtain data on the pulse blood filling.

\section{Selection of modeling tools}

In electrical impedance methods, it is proposed to use highfrequency currents that will pass through the bioobject. Accordingly, the mathematical apparatus will describe electromagnetic interactions taking into account the boundary conditions [15].

Calculations will be made with the help of Netgen Mesh Generator. For calculation, it is necessary to determine electrical parameters of tissues. The main tissues considered in this simulation are bone, scalp, brain substance, eye, blood. Table I presents a summary of the set parameters [22].

TABLE I. RELATIVE PERMITTIVITY AND THE CONDUCTIVITY OF THE TISSUES

\begin{tabular}{|c|c|c|}
\hline Layer name & Conductivity $(\mathbf{S}$ / m) & Relative permittivity \\
\hline Scalp & 0.5370 & 3300 \\
\hline Bone & 0.0083 & 472 \\
\hline Brain substance & 0.1340 & 3220 \\
\hline Blood & 0.7030 & 5120 \\
\hline Eye & 0.4990 & 1060 \\
\hline
\end{tabular}

\section{Construction of the geometry of the bioobject}

The images obtained with the help of magnetic resonance tomography were analyzed to take into account all the layers entering into the mathematical model. The Fig.2 shows a snapshot reconstructed from MRI data (the NeuroImaging \& Surgical Technologies Lab laboratory database) [23].

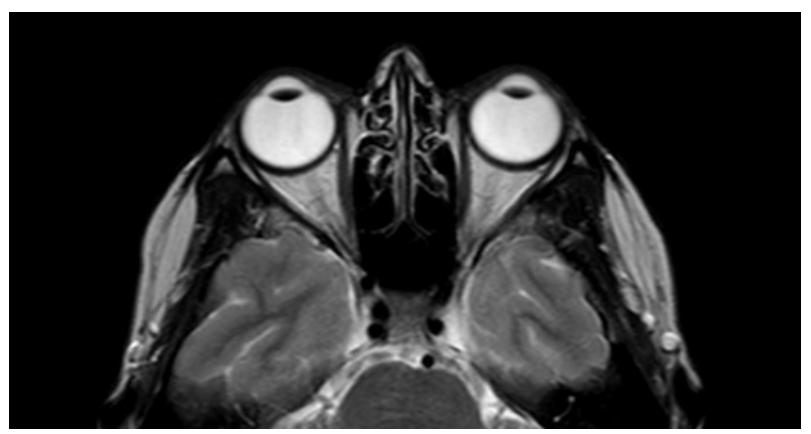

Fig.2. Snapshot of MRI with identification of the main biological structures of the eye

20 MRI snapshots from [23] were analyzed for the further reconstruction of the object geometry. The averaged geometry of the object was constructed on the basis of received data. The model is represented in the Fig.3. Since this model is intended only for determining the distribution of the probing current in the layers.

Six metal electrodes with a diameter of $5 \mathrm{~mm}$ are represented. The distance between the electrodes is fixed and has been chosen taking into account the anatomical structure of the skull (varies from 30 to $40 \mathrm{~mm}$ ). The current source is located on the surface of the leftmost electrode; the current strength is $3 \mathrm{~mA}$ [24]. The electrodes located between them the measuring electrodes (see Fig.3).

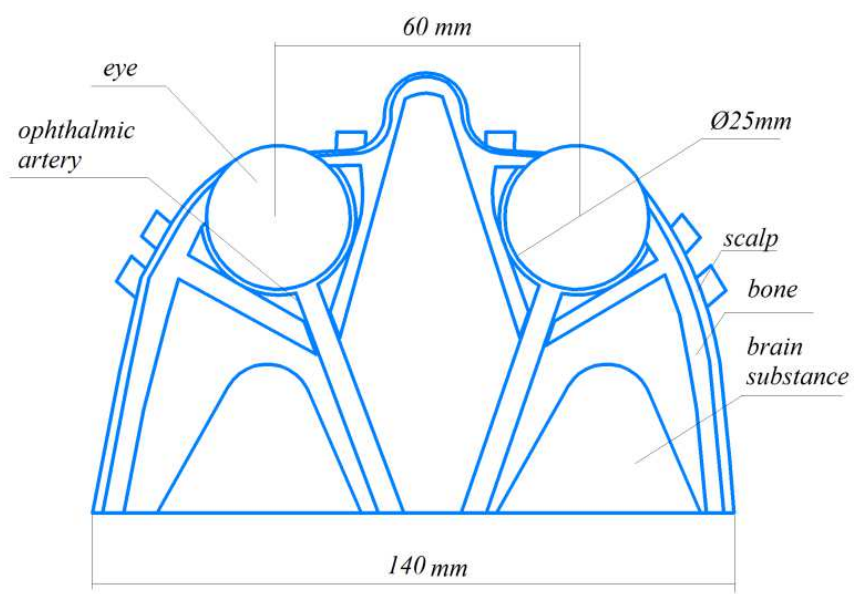

Fig.3. The geometry of the head front section in our modeling

\section{E. Setting the basic simulation parameters}

After downloading the obtained geometry of the bioobject into the software package, it is possible to specify parameters the values of conductivity and relative permittivity for all layers. 
The calculations have been carried out by the finite element method. The propagation of equipotential flow lines (see Fig.4) have been analyzed at time $\mathrm{t}=0 \mathrm{~s}$ at an artery radius $\mathrm{r}=0.5 \mathrm{~cm}$.

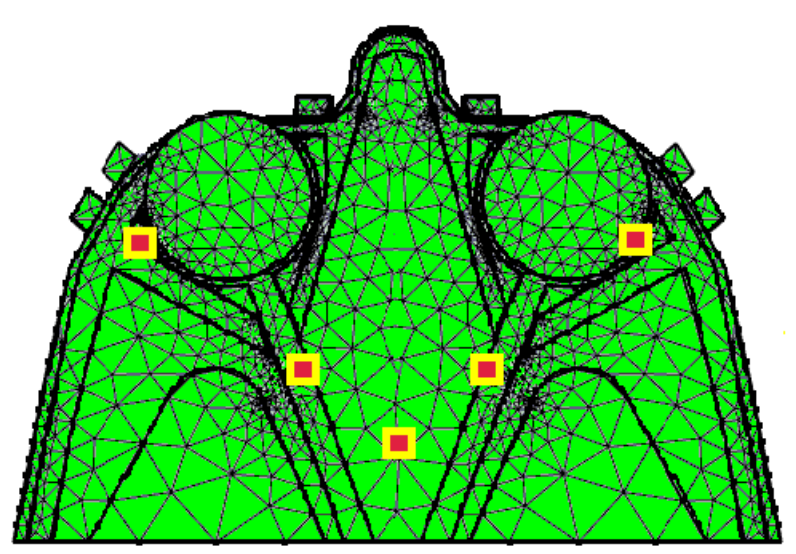

Fig.4. The distribution of equipotential lines in the our model

Due to the fact that the radius of the vessel varies with time due to the pulsations of the blood, we assigned its geometry as a variable value. To determine the required values, we used Doppler ultrasound signals. The Fig. 5 shows a signal recorded from the ophthalmic artery by the Doppler ultrasound method (Signal Processing Laboratory database) [25].

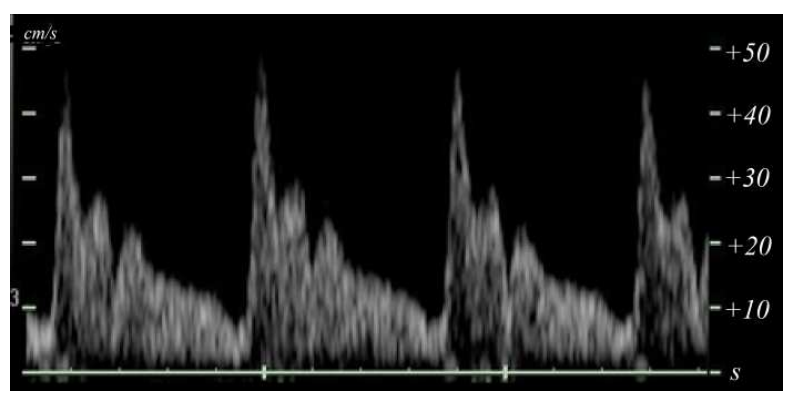

Fig.5. Doppler ultrasound signal of the ophthalmic artery

Doppler ultrasound shows a linear flow velocity in the vessel [25]. Pulsations of the radius of the blood vessel are associated with a change in the magnitude of the linear blood flow. Certain values of blood flow radius were stored in an array of values. The results obtained range from 0.35 to 0.50 $\mathrm{mm}$ per cardio interval. In our model, the geometry (radius) of the ophthalmic artery was changed within 1 second from 0.35 $\mathrm{mm}$ to $0.50 \mathrm{~mm}$.

The Table II shows an example of the resulting array of current density distribution values for the example of 5 equipotential lines (considered points are indicated in the Fig.4 for one line).
TABLE II. CHANGE VALUE (IN A/CM²) DEPENDING ON THE CHANGE OF THE VESSEL RADIUS

\begin{tabular}{|c|c|c|c|c|c|}
\hline $\begin{array}{c}\text { Line } \\
\text { Number }\end{array}$ & $\mathbf{1}$ & $\mathbf{2}$ & $\mathbf{3}$ & $\mathbf{4}$ & $\mathbf{5}$ \\
\hline 1 & 0.44 & 0.37 & 0.30 & 0.37 & 0.44 \\
\hline 2 & 0.41 & 0.38 & 0.29 & 0.38 & 0.41 \\
\hline 3 & 0.45 & 0.37 & 0.31 & 0.37 & 0.45 \\
\hline 4 & 0.44 & 0.38 & 0.29 & 0.38 & 0.44 \\
\hline 5 & 0.46 & 0.37 & 0.30 & 0.37 & 0.46 \\
\hline \multicolumn{5}{|c|}{ Limit of permissible error of quantities is $+/-10 \%$} \\
\hline
\end{tabular}

\section{RESULTS}

The main parameter for studying the hemodynamics of the eye vessels is the calculation such a significant parameter as stroke volume. The values of the stroke volume obtained by the Doppler ultrasound method were compared with the results obtained on the basis of model values. The values of stroke volume were calculated for three cardio cycles. The Doppler ultrasound signals were taken from the database [25]. Table 3 shows the obtained values on one example.

TABLE III. COMPARISON OF STROKE VOLUME VALUES

\begin{tabular}{|c|c|c|}
\hline $\begin{array}{c}\text { Number of cardio } \\
\text { cycle }\end{array}$ & $\begin{array}{c}\text { Stroke volume } \\
\text { (Doppler ultrasound), } \\
\text { ml }\end{array}$ & $\begin{array}{c}\text { Stroke volume (model } \\
\text { volumes), ml }\end{array}$ \\
\hline 1 & 2.00 & 1.75 \\
\hline 2 & 2.07 & 1.69 \\
\hline 3 & 2.05 & 1.70 \\
\hline
\end{tabular}

Limit of permissible error of quantities is $+/-10 \%$

For a sample of 20 signals, the mean value of the RMS did not exceed 0.3 , which may indicate the verification of the obtained model.

The practical application of the developed model can be the studying the relationship between blood filling of tissues and electrical conductivity. In particular, within the framework of this work, a study was made, based on the developed model, on the effect of changing the geometry of the object under consideration on electrical conductivity (Table 4).

TABLE IV. CHANGE IN RESISTANCE VALUE DEPENDING ON THE CHANGE OF THE VESSEL RADIUS

\begin{tabular}{|l|c|c|c|}
\hline \multicolumn{1}{|c|}{$\begin{array}{c}\text { Pulse curve } \\
\text { point }\end{array}$} & $\begin{array}{c}\text { Radius of the } \\
\text { vessel }(\mathbf{m m})\end{array}$ & $\begin{array}{c}\text { Diameter of } \\
\text { the eye } \\
\text { (mm) }\end{array}$ & $\begin{array}{c}\text { Obtained } \\
\text { resistance value } \\
\text { (Ohm) }\end{array}$ \\
\hline $\begin{array}{l}\text { The beginning of } \\
\text { a cardiocycle }\end{array}$ & 0.35 & 25.0 & 0.345 \\
\hline $\begin{array}{l}\text { The systolic } \\
\text { wave diastolic }\end{array}$ & 0.50 & 25.3 & 0.178 \\
\hline $\begin{array}{l}\text { The } \\
\text { wave }\end{array}$ & 0.40 & 25.1 & 0.227 \\
\hline
\end{tabular}

In the second part of the study, the resistivity values were varied with the unchanged geometry of the object (Table 5). 
TABLE V. Change IN THE RESISTANCE VALUE DEPENDING ON CONDUCTIVITY

\begin{tabular}{|l|c|c|}
\hline \multicolumn{1}{|c|}{ Pulse curve point } & $\begin{array}{c}\text { Conductivity of the } \\
\text { eye, } \mathbf{S} / \mathbf{m}\end{array}$ & $\begin{array}{c}\text { Obtained resistance } \\
\text { value, Ohm }\end{array}$ \\
\hline $\begin{array}{l}\text { The beginning of a } \\
\text { cardiocycle }\end{array}$ & 0.4990 & 0.286 \\
\hline The systolic wave & 0.5190 & 0.269 \\
\hline The diastolic wave & 0.4890 & 0.263 \\
\hline
\end{tabular}

Limit of permissible error of quantities is $+/-10 \%$

Comparing the values of Table 4 and 5 , it is obvious that the obtained values of resistances have significant differences. This may be due to fairly coarse changes in electrical conductivity. Thus, we can conclude that this model is workable, but it requires the specifications of certain parameters.

\section{CONCLUSION}

As a result of this work, a mathematical model has been developed to study the pulse blood filling of the anterior part of the head. In the future, it will allow to determine the levels of diagnostic signals, by changing the position of electrodes, to evaluate the accuracy of the obtained results.

\section{REFERENCES}

[1] P. Neittaanmäki, S. Repin and T. Tuovinen (Eds.). Mathematical Modeling and Optimization of Complex Structures; Series: Computational Methods in Applied Sciences. Springer International Publishing AG, Switzerland; E-book, XXI, 2016.

[2] C. Dym, Principles of mathematical modeling. Amsterdam: Elsevier Academic Press, 2004

[3] S. Banerjee, Mathematical Modeling: Models, Analysis and Applications. N.-Y.: Chapman and Hall/CRC, 2014.

[4] S. Pappalardo, "Mathematical modeling of biological systems", Briefings in Bioinformatics, Volume 14, Issue 4, 2013.

[5] L. Formaggia, A. Quarteroni and A. Veneziani, Cardiovascular mathematics. Milan: Springer, 2009.

[6] R. Brent, "A partnership between biology and engineering". Nature Biotechnology, vol. 22, no. 10, pp. 1211-1214, 2004.

[7] P. V. Luzhnov, D. M. Shamaev, E. N. Iomdina, "Using quantitative parameters of ocular blood filling with transpalpebral rheoophthalmography". IFMBE Proceedings 65: pp.37-40, 2017.
[8] P. V. Luzhnov, D. M. Shamaev, A. A. Kiseleva, E. N. Iomdina, "Analyzing rheoophthalmic signals in glaucoma by nonlinear dynamics methods". IFMBE Proceedings 68/2: pp.827-831, 2018.

[9] O. Wolkenhauer, "The role of theory and modeling in medical research", Frontiers in Physiology, vol. 4, 2013.

[10] M. Mark, Mathematical modeling. Edition: 3rd ed. Publisher: Singapore : Elsevier (Singapore), 2007.

[11] T. Witelski, M. Bowen. Methods of mathematical modelling continuous systems and differential equations, Cham : Springer, 2015.

[12] E. Tom, K. Schulman, "Mathematical models in decision analysis". Infec Control Hosp Epidemiol, vol. 18, pp. 65-73, 1997.

[13] R Patterson, "Electrical Impedance Tomography: Methods, History, and Applications (Institute of Physics Medical Physics Series)", Physics in Medicine and Biology, vol. 50, no. 10, pp. 2427-2428, 2005.

[14] Frerichs, J. Scholz and N. Weiler, "Electrical Impedance Tomography and its Perspectives in Intensive Care Medicine", Intensive Care Medicine, pp. 437-447, 2006.

[15] A. Adler, R. Gaburro, W. Lionheart, "Electrical Impedance Tomography", in Handbook of Mathematical Methods in Imaging, 2nd ed O Scherzer (Ed), Springer, 2016.

[16] D. M. Shamaev, P. V. Luzhnov, E. N. Iomdina, "Modeling of ocular and eyelid pulse blood filling in diagnosing using transpalpebral rheoophthalmography". IFMBE Proceedings 65: pp.1000-1003, 2017.

[17] D. M. Shamaev, P. V. Luzhnov, E. N. Iomdina, "Mathematical modeling of ocular pulse blood filling in rheoophthalmography". IFMBE Proceedings 68/1: pp.495-498, 2018.

[18] L. Callegaro, Electrical impedance. Boca Raton: CRC Press, Taylor \& Francis Group, 2016.

[19] R. D. Sinelnikov, Y. R. Sinelnikov, Atlas of human anatomy: In 4 volumes. - 7 th ed., Rev. and additional. - T. 1. - Moscow: New Wave, 2007.

[20] Luzha D. X-ray anatomy of the vascular system. Budapest: Publishing House of the Hungarian Academy of Sciences, 1973.

[21] D. M. Shamaev, P. V. Luzhnov, T. O. Pika, E. N. Iomdina, A. P. Kleyman, A. A. Sianosyan, "Applying transpalpebral rheoophthalmography to monitor effectiveness of the treatment of patients with glaucoma". International Journal of Biomedicine 6(4): pp.287-289, 2016.

[22] C. Gabriel, Compilation of the dielectric properties of body tissues at RF and microwave frequencies / King.s College London. 1996.

[23] "BITE: Brain Images of Tumors for Evaluation database NIST", Nist.mni.mcgill.ca, 2018. [Online]. Available: http://nist.mni.mcgill.ca/?page_id=672. [Accessed: 08- May- 2018].

[24] C. Dimas, P. Tsampas, N. Ouzounoglou, and P. Sotiriadis, "Development of a modular 64-electrodes Electrical Impedance Tomography system", 2017 6th International Conference on Modern Circuits and Systems Technologies (MOCAST), 2017.

[25] "Ultrasound image database | SPLab", Splab.cz, 2018. [Online]. Available: http://splab.cz/en/download/databaze/ultrasound. [Accessed: 08- May- 2018]. 